\title{
Volcanic ash and respiratory symptoms in children on the island of Montserrat, British West Indies
}

\author{
L Forbes, D Jarvis, J Potts, P J Baxter
}

Occup Environ Med 2003;60:207-211

See end of article for authors' affiliations

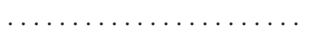

Correspondence to: Dr D Jarvis, Department of Public Health Sciences, King's College London, Capital House, 42 Weston Street, London SE 1 3QD, UK; deborah.jarvis@kcl.ac.uk

Accepted 25 September 2002
Background: In July 1995 the volcano on the West Indian island of Montserrat erupted after being inactive for several hundred years. Since then, clouds of ash have been released intermittently from the volcano. Some of this ash is $<10 \mu \mathrm{m}$ in diameter and therefore respirable. Concerns were raised that the particles might cause respiratory problems.

Aims: To evaluate whether ashfalls had any effect on the respiratory health of children in Montserrat. Methods: A survey of asthma diagnoses, respiratory symptoms, exercise induced bronchoconstriction (EIB), and current and previous exposure to volcanic ash was carried out in schools in Montserrat during February 1998.

Results: Questionnaire information was available for nearly $80 \%$ of the 443 children on the school rolls. The prevalence of wheeze symptoms in the previous 12 months was $18 \%$ in children aged 12 years and under and $16 \%$ in children aged 13 years and over. In children aged 12 and under, the prevalence of wheeze was greater in those who had ever been heavily or moderately exposed to volcanic ash compared with the group who had only ever been exposed to low levels (wheeze in last 12 months: odds ratio (OR) 4.30; wheeze ever: OR 3.45). The prevalence of EIB in 8-12 year olds was about four times higher in those who were currently heavily exposed to volcanic ash (OR 3.85) compared to those currently exposed to low levels.

Conclusions: Volcanic ash emissions adversely affected the respiratory health of Montserrat children. The findings emphasise the need to limit exposures of children to volcanic ash and ensure the appropriate management of respiratory symptoms.
O n 18 July 1995, the Soufriere Hills volcano, on the West Indian island of Montserrat, started to erupt after a repose period of over four hundred years. The island is a British Overseas Territory in the Lesser Antilles arc. Shaped like a pear, it is $17 \mathrm{~km}$ long and $10 \mathrm{~km}$ wide, with the summit of the volcano ( $1000 \mathrm{~m}$ above sea level) only $5 \mathrm{~km}$ from the now devastated capital Plymouth in the southern part of the island. The population had to be relocated in stages during 1996-97, eventually to the northern part of the island as the activity escalated, with most of the original population of 12000 people leaving the island altogether. By the time this study began in February 1998, about 3500 people were living in Montserrat in the northern part of the island outside the official exclusion zone around the volcano.

The eruption proceeded with the growth of a lava dome, a massive pile of hot rock at temperatures over $800^{\circ} \mathrm{C}$, which began slowly to fill the crater. Collapses of the dome formed pyroclastic flows, which are devastating hot clouds of gas and rock fragments that travel at speed down the flanks of the volcano. These flows produced convective clouds of ash that rose hundreds to thousands of metres. Less commonly tall columns of ash were emitted in explosions or venting episodes. During 1996-98, ash fell frequently over the island, mostly in the southern and lower central areas (see fig 1), which was also the area of greatest direct hazard from volcanic activity.

The main ashfall deposits from the lava dome collapses comprised $13-20 \mathrm{wt} \%$ particles less than $10 \mu \mathrm{m}$ in diameter $\left(\mathrm{PM}_{10}\right)$ and which contained $10-30 \mathrm{wt} \%$ of cristobalite, a form of crystalline silica that can cause silicosis. ${ }^{1}$ About $1-8 \mathrm{wt} \%$ was less than $2 \mu \mathrm{m}$ in mean diameter. During periods of frequent ashfalls in 1997-98 levels of $\mathrm{PM}_{10}$ regularly exceeded the UK air quality standard for particles (24 hour running average: $\left.50 \mu \mathrm{g} / \mathrm{m}^{3}\right){ }^{2}$ Peak $\mathrm{PM}_{10}$ levels during ashfalls could reach $150 \mathrm{mg} / \mathrm{m}^{3}$, when visibility was temporarily lost. The dry, fine deposits of ash were readily suspended by human activity, so personal exposures were potentially very high. The fine ash infiltrated homes, offices, and schools, as most buildings were of a traditional open design to keep them cool. Although the authorities issued advice on limiting ash exposure, such as wearing of masks and damping down ash around houses and schools, the extent to which these measures were effective is unclear.

As the eruption proceeded, there were anecdotal reports of, and local concerns about, increased respiratory symptoms in children living in ashfall areas. This study was conducted to determine the prevalence of asthma and asthma-like symptoms, and assess the association between exposure to ash, and respiratory symptoms and exercise induced bronchoconstriction (EIB) in children in Montserrat during the crisis.

\section{METHODS}

In February 1998 we asked carers (mostly parents) of all children aged 12 and under attending school in Montserrat to complete a questionnaire. This included the questions used in the International Study of Asthma and Allergies in Children (ISAAC), ${ }^{3}$ which assess the lifetime and 12 month period prevalence of respiratory symptoms suggestive of asthma. We added questions on health service use and medications over the previous 12 months, as well as information on areas of residence since the eruption began. Children aged 13 and over completed a similar questionnaire in the classroom.

During the following week all children aged between 8 and 12 years were asked to perform exercise testing following the

Abbreviations: EIB, exercise induced bronchoconstriction; PEFR, peak expiratory flow rate; PM, particulate matter; TSP, total suspended particulate 


\section{Main messages}

- Children who lived in areas recognised to have undergone high exposure to volcanic ash reported more respiratory symptoms than those who lived in areas with lower exposure.

- Children who lived in areas recognised to have undergone high exposure to volcanic ash had more exercise induced bronchoconstriction than those who lived in areas with lower exposure.

- Few children living in Montserrat during the period of the eruption and who reported they had asthma were receiving treatment as recommended by current international guidelines.

\section{Policy implications}

- Children living in Montserrat should be encouraged to take appropriate measures to reduce their exposure to ash during periods of ashfall.

- Appropriate community based interventions should be developed and implemented to reduce exposure of populations of children to volcanic ash.

- Measures should be taken to ensure that children with respiratory symptoms receive appropriate treatment for their condition.

method described by Burr and colleagues, ${ }^{4}$ after written consent was obtained from their parents. We measured peak expiratory flow rate (PEFR) five times before six minutes of free running and again five minutes after completion of the run. The percentage difference of the two measures (before and after) was calculated using the mean of the three highest PEFR readings.

Two people with close knowledge of the island over the period of the eruption ( $\mathrm{PB}$ and a volcanologist at the Montserrat Volcano Observatory) together categorised each of the reported residential locations into areas of high, moderate, or low levels of exposure to ash without knowledge of the symptoms reported by the children. The classification was based on the accumulated depths of compacted ash from 1995 to 1998 (see fig 1). While some measures of airborne ash were available, depth of ash was considered a more accurate measure of total exposure at each residential location.

The prevalences of symptoms, use of health services, and EIB in children aged 12 years and under, and in children 13 and over, were calculated. The association of respiratory symptoms, use of health services, and EIB with exposure to volcanic ash was determined by logistic regression with adjustment for age, sex, and parental smoking. We analysed the data using the statistical package Stata (STATA corporation, 702 University Drive East, College Station, Texas 77840).

\section{RESULTS}

Three hundred and eighty three questionnaires were returned from $86.5 \%$ of the 443 children on the school rolls. Three hundred and fifty (79.0\%) contained complete information about wheezing symptoms, 240 in children aged 12 and under and 110 aged 13 and over.

Table 1 shows the prevalences of reported respiratory symptoms, use of medication, and visits to a doctor in the past 12 months for respiratory symptoms. The prevalence of wheeze in the previous year was $17.5 \%$ in children aged 12 and under, and $16.4 \%$ in children aged 13 and over. A diagnosis of asthma was given in $10.1 \%$ of the younger group and in $9.1 \%$ of the older group. Thirty nine (11.1\%) of the children had a parent who smoked.

Current place of residence was available for 342 of the 350 children with complete information about wheezing (97.7\%).

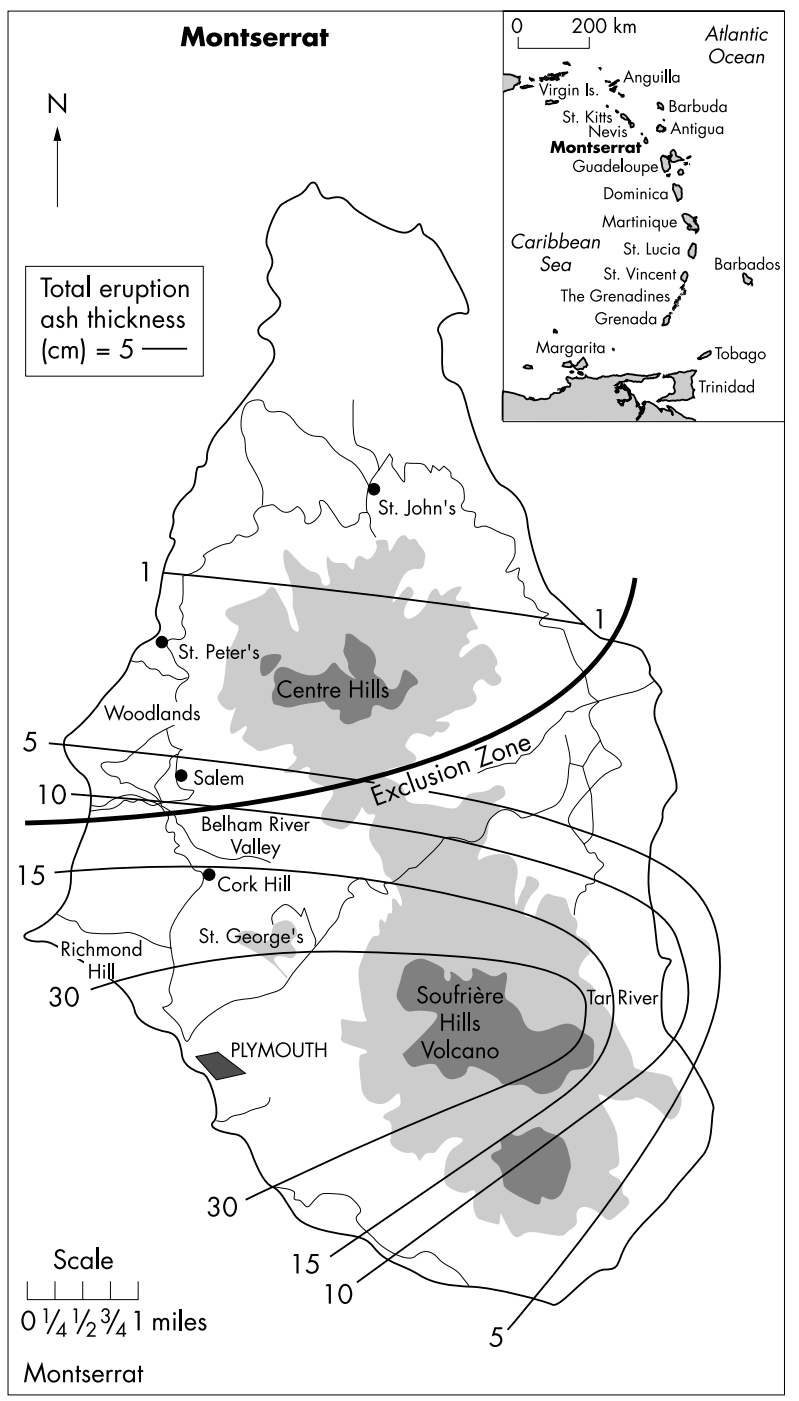

Figure 1 Montserrat.

Forty one children (12.0\%) were currently living in an area of heavy ash exposure, one child $(0.3 \%)$ in an area of moderate exposure, and 300 children $(87.7 \%)$ in areas of low exposure. A complete list of places of residence since July 1995 was provided by $324(92.6 \%)$. One hundred and eighty five children $(57.1 \%)$ reported that they had at some point since the eruption started, lived in areas heavily exposed to ash emissions; $18(5.6 \%)$ had lived in areas of moderate exposure; and 121 $(37.3 \%)$ had only lived in areas of low exposures.

For the analysis of the relation between exposure to ash emissions and respiratory symptoms and EIB, the children with moderate and heavy exposure, either ever or current, were treated as one group because of the small numbers of children with moderate exposure. Table 2 shows odds ratios for symptoms and health service use in children who were currently living or had ever lived in moderate or heavy ash exposure areas in the 12 and under and the 13 and over age groups separately after adjustment for age, sex, and parental smoking. Children aged 12 and under who had ever lived in areas of moderate or heavy ash exposure had a significantly greater prevalence of reported wheeze ever (OR 3.45, 95\% CI 1.69 to 7.04 ) and wheeze in the past 12 months (OR 4.30, 95\% CI 1.70 to 10.86 ) compared to those who had always lived in low exposure areas. Similar associations were observed for cough and use of health services in this younger age group and for symptoms in the older children although the observed differences were not statistically significant. 
Table 1 Prevalence of respiratory symptoms, use of health services, impact on activities, and diagnosed asthma

\begin{tabular}{lll}
\hline & Number reporting (\%) & \\
\cline { 2 - 3 } & 12 years and under & 13 years and over \\
\hline & (Data available for & (Data available for \\
& 240 children) & 110 children) \\
Wheeze ever* & $67(27.9)$ & $30(27.3)$ \\
In the past 12 months & & $18(16.4)$ \\
Wheeze & $42(17.5)$ & $13(11.8)$ \\
Sleep disturbed by wheezing & $28(11.7)$ & $3(2.7)$ \\
Speech limiting attacks of wheeze & $8(3.3)$ & (Data available for \\
In the past 12 months & $($ Data available for & 110 children) \\
Dry cough & 218 children) & $48(43.6)$ \\
Seen a doctor for breathing problems & $55(25.2)$ & $12(10.9)$ \\
Medication for breathing & $23(10.6)$ & $25(22.7)$ \\
Breathing problems interfered with normal activities & $36(16.5)$ & $5(2.7)$ \\
"quite a bit" & $4(1.8)$ & $5(2.7)$ \\
More than 5 days school absence because of & $6(2.8)$ & $10(9.1)$ \\
breathing problems & & \\
Asthma ever* & $22(10.1)$ & \\
\hline * wheeze "ever" and asthma "ever" = lifetime prevalence. &
\end{tabular}

Children aged 12 and under who were currently living in moderate or heavy ash exposure areas reported more wheeze and health service use but not cough, than those who currently lived in low exposure areas, but these differences did not reach statistical significance. No similar associations between exposure and symptoms were found in children aged 13 and over.

Exercise tests were performed on 141 children aged 8-12 years $(86.0 \%$ of the 164 children in this age group who provided questionnaire information). Seven of these $(5.0 \%$, $95 \%$ CI $2.0 \%$ to $10.0 \%$ ) had a positive test as conventionally defined by a $15 \%$ fall in PEFR. In view of this small proportion, for the analysis of the association between EIB and exposure to ash, a fall in PEFR of $10 \%$ was used to define a positive test. Nineteen children (13.5\%, 95\% CI $8.3 \%$ to $20.2 \%$ ) had EIB by this definition. None of them had a parent who smoked. Table 3 shows the association between EIB and exposure to volcanic ash emissions. The relative risk of EIB, defined as a 10\% fall in PEFR, was nearly four times greater in children who currently lived in moderate or heavy ash exposure areas than in those who had currently lived in low exposure areas after adjustment for age and sex.

Of the children who reported wheeze in the past 12 months, none reported current use of a corticosteroid inhaler. Four children reported having a $\beta$ agonist inhaler.

\section{DISCUSSION}

This study shows that children who had ever lived in areas with moderate or heavy exposure to ash since July 1995 reported more respiratory symptoms and use of health services for respiratory problems than children who had never lived in these areas. Objective measures of lung function supported this finding.

Overall we achieved a response of almost $80 \%$ to the questionnaire. No information was available about those for whom data were not collected, though they may have differed from responders in a variety of ways. However, non-response is unlikely to cause false positive associations of exposure with disease in epidemiological studies unless complex response biases are present.

The associations between exposure to volcanic ash and reported morbidity may have been biased by over-reporting of symptoms in children who were exposed and who had erroneously attributed their symptoms to an effect of volcanic ash. Conversely the study participants may have underreported symptoms if they had believed that the results were to be used to justify unwanted relocation. While both underand over-reporting of symptoms may have occurred, EIB is an objective measure, so reporting bias cannot fully explain our findings.

What effect migration out of the island had on our estimates of association between living in a higher ash exposure area and respiratory health is not clear. It is possible that those who emigrated from higher exposure areas were of higher socioeconomic status and may have been healthier, with fewer respiratory symptoms than those who stayed behind. For this to explain the association we found, migration away from the island from low exposure areas would have to be unrelated to socioeconomic status, which seems unlikely. We do not have reliable data on the respiratory health or socioeconomic status of children who emigrated, though asthma was frequently cited as a medical condition among families who left under the Assisted Passage Scheme.

The prevalence of wheezy symptoms in Montserrat was similar to that found in a recent survey of Barbados children carried out as part of ISAAC. ${ }^{5}$ The prevalence of EIB in Montserrat (5.0\%) was similar to South Africa (4.1\%), higher than Sweden (2.1\%), and lower than New Zealand (12.2\%) and Wales $(7.7 \%)$, in studies following a similar protocol. ${ }^{4}$ Comparing the prevalence with more stable populations to gain information about the possible effect of ash emissions is of limited value as we do not know the prevalence before the eruption or the extent to which emigration after the crisis influenced prevalence.

Anxiety over the effects of ashfalls is common in volcanic crises, but as eruptions are infrequent, little information exists on the respiratory health effects. The long duration of the Montserrat eruption is unusual. Surveys of people living near ash eruptions show increases in reports of respiratory symptoms, ${ }^{67}$ and increased numbers of health service attendances for respiratory symptoms, ${ }^{8-10}$ including in children. ${ }^{112}$ However, until now no published studies have shown clearly that volcanic ash exposure is associated with asthma-like symptoms or EIB in children. In Montana, a state affected by moderate ashfall from the 18 May 1980 eruption of Mount St Helens, elementary school children taking part in an air pollution study had had their lung function recently recorded. 


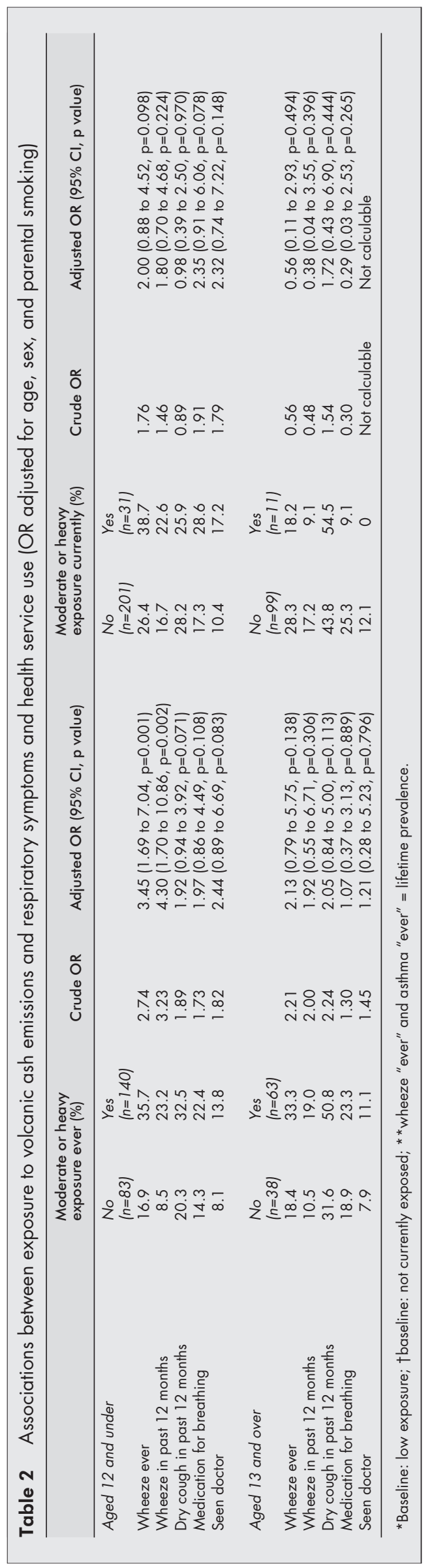

On 23 May, when schools were reopened following the eruption, no change in their lung function was found..$^{13}$ The ambient total suspended particulate (TSP) concentration was between 948 and $11054 \mu \mathrm{g} / \mathrm{m}^{3}$ during 19-22 May, but as people had been advised to stay indoors until 23 May the actual exposure may have been lower. Buist et al found no change in lung function over a two week period in 101 children attending a summer camp in Oregon affected by the 12 June eruption of Mount St Helens, when daytime TSP levels were 800 and $2300 \mu \mathrm{g} / \mathrm{m}^{3}$, and respirable dust levels averaged 170 $\mu \mathrm{g} / \mathrm{m}^{3}{ }^{14}$ No increase in asthma-like symptoms was found in children living near Mount Sakurajima, Japan, during the frequent ashfalls from its almost daily eruptions in 1991-93, but the ash was mainly coarser than $\mathrm{PM}_{10}{ }^{15-17}$

In contrast, the high individual exposures on Montserrat lasted for over two years, during which there were frequent light ashfalls and repeated resuspension of clouds of very fine, respirable ash. Large eruptions (ground deposit over $1 \mathrm{~cm}$ ) leading to temporary restriction of transport and closure of workplaces and schools were rare. The fine ash readily penetrated the open style housing, so indoor exposures were also high. However, rainfall almost totally prevented the resuspension of ash by wind or human activity, including children playing outdoors. Although Montserrat has frequent rainfall, in 1997 most days were dry and dusty. The disruption of medical services and lack of availability of effective asthma medication, which had not been evident before the survey, may also have contributed to our findings.

Epidemiological studies have shown associations between ambient $\mathrm{PM}_{10}$ levels and hospital admissions for respiratory illnesses, and mortality from cardiac and respiratory diseases. ${ }^{18}$ However, the association is less consistent for asthma. ${ }^{18} 19$ The coarse fraction of $\mathrm{PM}_{10}\left(\mathrm{PM}_{2.5-10}\right)$ is generally considered to be less toxic than the fine $\left(<\mathrm{PM}_{2.5}\right)$ fraction, and crustal derived particles, such as volcanic ash, less toxic than those generated by traffic exhausts, ${ }^{20}$ but both fractions may induce asthmatic or bronchitic responses. ${ }^{21}$

As well as their size, the surface properties of particles, for example, the presence of transition metals, could trigger inflammatory processes by initiating the release of free radicals. ${ }^{21}$ Freshly erupted volcanic ash has an unweathered surface that can carry substances such as trace metals, hydrocarbons, and acids emitted in the eruption. Hydrocarbons formed from burning vegetation are unlikely to have been present as most of the pyroclastic flows were down the Tar River Valley, which had been stripped of vegetation early in the eruption. Sulphuric, hydrochloric, and hydrofluoric acids in the erupted plume are readily adsorbed onto the surfaces of ash particles, ${ }^{22}$ and these could cause irritative effects on airways. These acids may also react with glass and silicate components of the ash, forming calcium sulphate and sodium chloride as precipitated coatings. On contact with moisture these substances may be taken into solution to produce corrosive acids that burn foliage, but the soluble acid content of the ash was usually low. Increased allergen exposure is also an unlikely explanation: fresh volcanic ash is sterile and free from endotoxin or fungal spore contamination. Routine monitoring of sulphur dioxide since 1996 has shown that the gas plume rarely reached the ground under any weather conditions, so direct exposure to volcanic gases was unlikely to have caused respiratory symptoms. Air pollution from vehicle emissions on this unspoilt, verdant island was minimal before or since the eruption.

Our findings provide evidence that the respiratory health of children was affected in the volcanic crisis, as a result of the long duration of exposure to high ambient levels of respirable ash particles. Further eruptive activity is likely for some years, though the escalation of activity in 1997 had not been repeated by mid-2001. Modelling, however, has shown that the probability of large deposits of ash accumulating in the occupied north part of the island is very low. ${ }^{23}$ We recommend 
Table 3 Exercise induced bronchoconstriction (EIB) and exposure to volcanic ash emissions in children aged 8-12 (odds ratios adjusted for age and sex)

\begin{tabular}{|c|c|c|c|c|}
\hline \multirow{2}{*}{$\begin{array}{l}\text { Exposure to moderate or } \\
\text { heavy levels of volcanic ash } \\
\text { emissions }\end{array}$} & \multicolumn{2}{|c|}{ Children with EIB ( $10 \%$ fall in PEFR after exercise) } & \multicolumn{2}{|c|}{ Children with EIB ( $15 \%$ fall in PEFR after exercise) } \\
\hline & Number (\%) & Adjusted OR (95\% Cl) & Number (\%) & Adjusted OR (95\% Cl) \\
\hline \multicolumn{5}{|c|}{ Ever exposed (baseline: never exposed to moderate or high ash emissions) } \\
\hline No & $5(11.1)$ & 1.00 & $1(2.2)$ & 1.00 \\
\hline Yes & $13(15.7)$ & $\begin{array}{l}1.55(0.51 \text { to } 4.71) \\
p=0.439\end{array}$ & $6(7.2)$ & $\begin{array}{l}3.48 \quad(0.41 \text { to } 29.93) \\
p=0.256\end{array}$ \\
\hline \multicolumn{5}{|c|}{ Currently exposed (baseline: not currently exposed to moderate or high ash emissions) } \\
\hline No & $12(10.3)$ & 1.00 & $5(4.3)$ & 1.00 \\
\hline Yes & $6(31.6)$ & $\begin{array}{l}3.85(1.22 \text { to } 12.11) \\
p=0.021\end{array}$ & $2(10.5)$ & $\begin{array}{l}2.58 \quad(0.46 \text { to } 14.55) \\
p=0.283\end{array}$ \\
\hline
\end{tabular}

that the health sector response in volcanic eruptions should include measures to ensure that the respiratory health of children is adequately monitored and treated and appropriate advice given on limiting exposure to fine ash.

\section{ACKNOWLEDGEMENTS}

We are indebted to the parents, the children, and the teachers for their co-operation. We thank Dr S Young, Montserrat Volcano Observatory, for his advice, and Dr T Carter and Dr J Rashbass for their assistance with undertaking the study in the schools. Dr A Searl, Institute of Occupational Medicine, Edinburgh, provided ash monitoring data. Chemical and physical studies of volcanic ash were undertaken by Dr V Hards, Ms B Vickers, and Mr R Nicholson of the British Geological Survey. We are grateful to Prof P Burney for his advice and support.

\section{Authors' affiliations}

L Forbes, D Jarvis, J Potts, Department of Public Health Sciences, King's College London, Capital House, 42 Weston Street, London SE I 3QD, UK

P J Baxter, Department of Public Health and Primary Care, Institute of Public Health, University of Cambridge, Forvie Site, Robinson Way, Cambridge CB2 2SR, UK

Funding: Department for International Development

\section{REFERENCES}

1 Baxter PJ, Bonadonna C, Dupree R, et al. Cristobalite in volcanic ash of the Soufriere Hills Volcano, Montserrat, British West Indies. Science 1999;283: 1 142-5

2 Expert Panel on Air Quality Standards. Particles. London: Dept of Environment, 1998.

3 Asher MI, Keil U, Anderson HR, et al. International study of asthma and allergies in childhood (ISAAC): rationale and methods. Eur Respir $J$ 1995;8:483-91.

4 Burr ML, Limb ES, Andrae S, et al. Childhood asthma in four countries: a comparative survey. Int J Epidemiol 1994:23:341-7.

5 Howitt ME, Roach TC, Naidu RO. Prevalence of asthma and wheezing illnesses in Barbadian school children. West Indian Med J 1998;47(suppl 2);22-3.
6 Baxter PJ, Ing R, Falk H, et al. Mount St Helens eruptions: the acute respiratory effects of volcanic ash in a North American community. Arch Environ Health 1983:38:138-43.

7 Horton RJM, McCaldin RO. Observations on air pollution aspects of Irazu volcano, Costa Rica. Public Health Reports 1964;79:925-9.

8 Baxter $\mathbf{P}$, Ing R, Falk $\mathrm{H}$, et al. Mount St Helens Eruptions, May 18 to June 12 1980. An overview of the acute health impact. JAMA $1981 ; 246: 2585-9$.

9 Malilay J, Real MG, Ramirez Vanegas A, et al. Public health surveillance after a volcanic eruption: lessons from Cerro Negro, Nicaragua, 1992. Bull PAHO 1996;30:218-26

10 Nania J, Bruya TE. In the wake of Mount St Helens. Ann Emerg Med 1982;11:184-91.

11 Leus X, Kintanar C, Bowman V. Asthmatic bronchitis associated with a volcanic eruption in St Vincent, West Indies. Disasters 1981;5:67-9.

12 Kraemer MJ, McCarthy MM. Childhood hospitalisation rates in Spokane County, Washington: impact of volcanic ash air pollution. J Asthma 1985;22:37-43.

13 Johnson KG, Loftsgaarden DO, Gideon RA. The effects of Mount St Helens volcanic ash on the pulmonary function of 120 elementary school children. Am Rev Respir Dis 1982;126:1066-9.

14 Buist AS, Johnson LR, Vollmer WM, et al. Acute effects of volcanic ash from Mount Saint Helens on lung function in children. Am Rev Respir Dis 1983;127:714-19.

15 Uda $\mathbf{H}$, Akiba S, Hatano $\mathrm{H}$, et al. Asthma-like disease in the children living in the neighbourhood of Mt Sakurajima. J Epidemiol 1999:9:27-31.

16 Yano E, Yokoyama $Y$, Higashi $H$, et al. Health effects of volcanic ash: a repeat study. Arch Environ Health 1990;45:367-73.

17 Yano E, Yokoyama Y, Nishii S. Chronic pulmonary effects of volcanic ash: an epidemiologic study. Arch Environ Health 1986:41:94-9.

18 Anderson HR. Health effects of air pollution episodes. In: Holgate ST, Samet JM, Koren HS, Maynard RL, eds. Air pollution and health. San Diego: Academic Press, 1999.

19 Burney P. Air pollution and asthma: the dog that doesn't always bark. Lancet 1999;353:859-60.

20 Schwartz J, Norris G, Larson T, et al. Episodes of high coarse particle concentrations are not associated with increased mortality. Environ Health Perspect 1999;107:339-42.

21 Expert Panel on Air Quality Standards. Airborne particles: what is the appropriate measurement on which to base a standard? London: Department of Environment, Transport and the Regions, 2001.

22 Gilbert JS, Lane SJ, Sparks RSJ, et al. Charge measurements on particle fallout from a volcanic plume. Nature 1991;349:598-600.

23 Bonadonna C, Sparks RSJ. Assessment of tephra fall hazard and risk for Montserrat, West Indies. Unpublished report. London: DFID, 2000. 